\title{
1 On the Operating Mode of Bimetallic Systems for Environmental
}

\section{Remediation}

\author{
Noubactep C.
}

Angewandte Geologie, Universität Göttingen, Goldschmidtstraße 3, D - 37077 Göttingen, Germany. e-mail: cnoubac@ @wdg.de; Tel. +49 55139 3191, Fax: +49 551399379

\section{Abstract}

This letter challenges the concept that $\mathrm{Fe}^{0} / \mathrm{Me}^{0}$ bimetallic systems enhance contaminant reduction on $\mathrm{Me}^{0}$ surfaces. It is shown on a pure thermodynamic perspective that any enhancement of contaminant reduction by $\mathrm{Fe}^{0}$ in the presence of a second more electropositive elemental metal $\left(\mathrm{Me}^{0}\right)$ is the result of an indirect process resulting from iron corrosion. This demonstration validates the concept that aqueous contaminant removal in the presence of $\mathrm{Fe}^{0}$ mostly occurs within an in-situ generated oxide film on $\mathrm{Fe}^{0}$.

Keywords: Adsorption; Bimetallic system; Co-precipitation, Zerovalent iron; Reduction.

A metallic surface can be involved in chemical reactions in various ways: a metallic material can serve as a redox agent or catalyst, facilitating a reaction, or it can release metal species into the system $[1,2]$. Bemental iron $\left(\mathrm{Fe}^{0}\right)$ and $\mathrm{Fe}^{0} / \mathrm{Me}^{0}$ bimetallic systems used in water remediation $\left(\mathrm{Fe}^{0}-\mathrm{H}_{2} \mathrm{O}\right.$ systems $)$ are typical systems were all these three reaction paths might be involved: (i) $\mathrm{Fe}^{0}$ might serve as reducing agent (direct reduction), (ii) $\mathrm{Fe}^{0}$ surface might serve a catalyst for instance for the reduction through molecular $\left(\mathrm{H}_{2}\right)$ or atomic hydrogen $(\mathrm{H})$ and (iii) $\mathrm{Fe}^{0}$ might release $\mathrm{Fe}^{\mathrm{II}}$ and $\mathrm{H} / \mathrm{H}_{2}$ into the system. A Fe $/ \mathrm{Me}^{0}$ system is a system where the metallic surface should serve as a catalyst for contaminant reduction through hydrogen $\left(\mathrm{H} / \mathrm{H}_{2}\right)$. 
A survey of the voluminous literature on environmental remediation with $\mathrm{Fe}^{0}$ shows that all factors increasing $\mathrm{Fe}^{0}$ oxidation enhance contaminant removal. These factors include (i) the presence of molecular oxygen [3], (ii) the addition of a second more electropositive metal (e.g. $\mathrm{Ag}^{0}, \mathrm{Co}^{0}, \mathrm{Cu}^{0}, \mathrm{Ni}^{0}, \mathrm{Pd}^{0}, \mathrm{Pt}^{0}, \mathrm{Ru}^{0}$ ) yielding bimetallic systems [4,5], and (iii) increasing the surface area of iron by reducing its particle size [4]. Increasing $\mathrm{Fe}^{0}$ oxidation is directly correlated with increased generation of iron corrosion products (e.g. iron oxyhydroxides) which are well-known for their adsorptive capacity for both organic and inorganic compounds [6]. Iron corrosion products are formed as an oxide film at the $\mathrm{Fe}^{0}$ surface. To reach the underlying $\mathrm{Fe}^{0}$ surface a contaminant molecule should migrate across the film.

In discussing aqueous contaminant removal in the presence of $\mathrm{Fe}^{0}$, reduction at the $\mathrm{Fe}^{0}$ surface and adsorption onto iron corrosion products have traditionally been evaluated as separate, independent processes that occur simultaneously or sequentially. Thereby the dynamic nature of the formation of the oxide film on $\mathrm{Fe}^{0}[8]$ has been almost overseen. However, during their formation and transformation iron corrosion products likely sequestrate foreign species, including contaminants [9]. Therefore, the author of ref. [9] has revisited the concept of reductive transformations $[3,10]$ and introduced a new concept considering adsorption and co-precipitation of contaminants with iron corrosion products as primordial removal mechanism. The present letter shows that the conception that bimetallic systems enhance reductive transformation by $\mathrm{Fe}^{0}$ is incompatible with the premise that $\mathrm{Fe}^{0}$ is the reducing agent in $\mathrm{Fe}^{0}-\mathrm{H}_{2} \mathrm{O}$ systems (statement 1). It has been reported that the presence of $\mathrm{Pd}^{0}$ speeds up the reduction reaction as follows: on the $\mathrm{Pd}^{0}$ surface, molecular hydrogen $\left(\mathrm{H}_{2}\right)$ from iron corrosion is adsorbed and dissociated into more reducing atomic $\mathrm{H}$; atomic $\mathrm{H}$ attacks chlorinated contaminants (R-X) and transforms them to $\mathrm{R}-\mathrm{H}$ and $\mathrm{Cl}^{-}$[11]. Therefore, the better well-dispersed the $\mathrm{Pd}^{0}$ in the $\mathrm{Fe}^{0} / \mathrm{Pd}^{0}$ system, the higher the catalytic effect. But, as recalled above, an universal oxide film shields the bimetallic surface [9,12]. Catalytic hydrodehalogenation is a well-known decontamination process [13]; it differs from the 
52 reductive dehalogenation reactions by $\mathrm{Fe}^{0}$ and $\mathrm{Fe}^{0} / \mathrm{Pd}^{0}$ systems in that the catalytic surface $53 \quad\left(\mathrm{Pd}^{0}\right)$ and the electron donor $\left(\mathrm{H}_{2}\right)$ are supplied as two separate reagents.

To demonstrate the absurdity of statement 1 , lets consider the bimetallic system $\mathrm{Fe}^{0} / \mathrm{Pd}^{0}$ and a chlorinated hydrocarbon $(\mathrm{RCl})$ to be reduced by the bimetallic. The involved electrode potentials $\left(\mathrm{E}^{0}\right)$ are: $0.915 \mathrm{~V}$ for the couple $\mathrm{Pd} / \mathrm{II} / \mathrm{Pd}^{0}, 0.41$ to $0.59 \mathrm{~V}$ for the couple $\mathrm{RCl} / \mathrm{R}^{\circ}[14]$, and $-0.44 \mathrm{~V}$ for the couple $\mathrm{Fe}^{\mathrm{II}} / \mathrm{Fe}^{0}$. The higher the $\mathrm{E}^{0}$ value, the stronger the reducing capacity of $\mathrm{Fe}^{0}$ for the oxidant of a couple. Comparing the three $\mathrm{E}^{0}$ values, it is evident that $\mathrm{Pd}^{\mathrm{II}}$ and $\mathrm{RCl}$ are concurrent oxidants for $\mathrm{Fe}^{0}, \mathrm{Pd}^{\mathrm{II}}$ been the strongest. Therefore, if any $\mathrm{RCl}$ removal enhancement is observed in the presence of $\mathrm{Pd}^{\mathrm{II}}$ it is indirectly related to $\mathrm{Fe}^{0}$ oxidation. Thus enhanced contaminant reduction by bimetallics $[4,5,15]$ is an argument for indirect reduction (by $\mathrm{Fe}^{\mathrm{II}}$ or $\mathrm{H} / \mathrm{H}_{2}$ within the oxide film on $\mathrm{Fe}^{0}$ ) [12]. Because of the omnipresence of the oxide film, even if the reducing agent is $\mathrm{H} / \mathrm{H}_{2}$, the reduction is not likely to occur at the $\mathrm{Pd}^{0}$ surface. On the other hand $\mathrm{Fe}^{\mathrm{II}}$ adsorbed onto the oxide film $\left(\mathrm{Fe}^{\mathrm{II}}(\mathrm{s})\right.$ or structural $\mathrm{Fe}^{\mathrm{II}}$ ) has been shown to be a very strong reducing agent [16].

For illustration, consider an ideal redox indicator for the titration of $\mathrm{Fe}^{0}$ by $\mathrm{Pd}^{\mathrm{II}}$ (Eq. 1) having a standard potential of $0.238 \mathrm{~V}$. The redox half-reaction of the indicator is described by equation 2 [17], where $\operatorname{Ind}_{\mathrm{ox}}$ is the coloured oxidized form of the indicator, $\operatorname{Ind}_{\mathrm{red}}$ is the corresponding colourless reduced form, $\mathrm{n}$ is the number of electrons transferred (typically 1 or 2 ), and $\mathrm{m}$ is the number of protons transferred (typically 0,1 or 2) and is dependent on the $\mathrm{pH}$.

The end of the titration $\left(\mathrm{Fe}^{0}\right.$ depletion) is detected by the appearance of a colour in the solution. This colouration of the solution corresponds to the oxidation of the reduced form of the indicator to the oxidized form (Eq. 3) by $\mathrm{Pd}^{2+}$ ions. To obtain accurate results, the lowest 
possible amount of indicator should be used. In the titration context, no one can claim that $\mathrm{Pd}^{\mathrm{II}}$ enhances the reduction of $\operatorname{Ind}_{\mathrm{ox}}$ by $\mathrm{Fe}^{0}$. $\mathrm{Pd}^{\mathrm{II}}$ oxidizes both $\operatorname{Ind}_{\mathrm{ox}}$ and $\mathrm{Fe}^{0}$. In this competition $\mathrm{Fe}^{0}$ is the stronger electron donor. Therefore, if any $\operatorname{Ind}_{\mathrm{ox}}$ reduction enhancement is observed in the presence of $\mathrm{Pd}^{\mathrm{II}}$, it can only indirectly be related to $\mathrm{Fe}^{0}$ oxidation. It is true that the surface of $\mathrm{Pd}^{0}$ and not dissolved $\mathrm{Pd}^{\mathrm{II}}$ is the catalyst for contaminant reduction by $\mathrm{H} / \mathrm{H}_{2}$. The $\mathrm{Pd}^{0}$ surface is however, shielded as a rule, and dissolved $\mathrm{Pd}^{\mathrm{II}}$ will (at least partly) co-precipitate with iron hydroxides and will no more be available for catalytic activity. In conclusion, $\mathrm{Pd}^{0}$ and other bimetallic elements $\left(\mathrm{Co}^{0}, \mathrm{Cu}^{0}, \mathrm{Ni}^{0}, \mathrm{Pt}, \mathrm{Ru}^{0} \ldots\right)$ can not significantly enhance contaminant reduction by elemental iron (electron from $\mathrm{Fe}^{0}$ or from $\mathrm{H} / \mathrm{H}_{2}$ ). Consequently, the reported increased contaminant removal by bimetallic systems is a result of secondary redox processes within the oxide film on $\mathrm{Fe}^{0}$ (electron from $\mathrm{Fe}^{\mathrm{II}}$ or from $\mathrm{H} / \mathrm{H}_{2}$ ). This conclusion is a further negation of the well-established concept of direct reductive transformations as major decontamination process $[9,12]$.

For the further development of the iron reactive wall technology target experiments should be performed to investigate the influence of hydrodynamic shear stress on the transport, transfer and reaction rates within the oxide film, as well as film detachment under experimental conditions pertinent to natural situations. This means that experiments must be performed under conditions which favour oxide film formation and transformation. Redox processes within a film on iron is well documented in the context of microbiologically influenced corrosion [18].

\section{Acknowledgments}

Thoughtful comments provided by Angelika Schöner (Martin-Luther-University of Halle, Germany) on the draft manuscript are gratefully acknowledged.

\section{References}

[1] M. Haukka, M. Jakonen, T. Nivajärvi, M. Kallinen, The subtle effects of iron-containing metal surfaces on the reductive carbonylation of $\mathrm{RuCl}_{3}$. Dalton Trans. 26 (2006), 3212-3220. 
104 [2] A.N. Nesmeyanov, R.Kh. Freidlina, E.C. Chukovskaya, R.G. Petrova, A.B. Belyavsky,

105 Addition, substitution, and telomerization reactions of olefins in the presence of metal

106 carbonyls or colloidal iron. Tetrahedron 17 (1962), 61-68.

107 [3] L.J. Matheson, P.G. Tratnyek, Reductive dehalogenation of chlorinated methanes by iron 108 metal. Environ. Sci. Technol. 28 (1994), 2045-2053.

109 [4] C.J. Lin, S.L. Lo, Y.H. Liou, Dechlorination of trichloroethylene in aqueous solution by 110 noble metal-modified iron. J. Hazard. Mater. 116 (2004), 219-228.

111 [5] R. Muftikian, Q. Fernando, N. Korte, A method for the rapid dechlorination of low

112 molecular weight chlorinated hydrocarbons in water. Water Res. 29 (1995), 2434-2439.

113 [6] G.E. Brown Jr., V.E. Henrich, W.H. Casey, D.L. Clark, C. Eggleston, A. Felmy, D.W.

114 Goodman, M. Grätzel, G. Maciel, M.I. McCarthy, K.H. Nealson, D.A. Sverjensky, M.F.

115 Toney, J.M. Zachara, Metal oxide surfaces and their interactions with aqueous solutions and 116 microbial organisms. Chem. Rev. 99 (1999), 77-174.

117 [7] S. Rakshit, C.J. Matocha, G.R. Haszler, Nitrate reduction in the presence of wüstite. J.

118 Environ. Qual. 34 (2005), 1286-1292.

119 [8] P. Schmuki, From Bacon to barriers: a review on the passivity of metals and alloys. J.

120 Solid State Electrochem. 6 (2002), 145-164.

121 [9] C. Noubactep, Processes of contaminant removal in " $\mathrm{Fe}^{0}-\mathrm{H}_{2} \mathrm{O}$ " systems revisited. The

122 importance of co-precipitation. Open Environ. J. 1 (2007), 9-13.

123 [10] E.J. Weber, Iron-mediated reductive transformations: investigation of reaction

124 mechanism. Environ. Sci. Technol. 30 (1996), 716-719.

125 [11] Y. Liu, F.L. Yang, P.L. Yue, G. Chen, Dechlorination of Chlorophenols by

126 Palladium/Iron. Water Res. 35 (2001), 1887-1890.

127 [12] C. Noubactep, A critical review on the mechanism of contaminant removal in $\mathrm{Fe}^{0}-\mathrm{H}_{2} \mathrm{O}$ 128 systems. Environ. Technol. 29 (2008), 909-920. 
129 [13] C.G. Schreier, M. Reinhard, Catalytic hydrodehalogenation of chlorinated ethylenes

130 using palladium and hydrogen for the treatment of contaminated water. Chemosphere 31

131 (1995), 3475-3487.

132 [14] A.L. Roberts, L.A. Totten, W.A. Arnold, D.R. Burris, T.J. Campbell, Reductive

133 elimination of chlorinated ethylenes by zero-valent metals. Environ. Sci. Technol. 30 (1996),

$134 \quad 2654-2659$.

135 [15] D.M. Cwiertny, S.T. Bransfield, A.L. Roberts, Influence of oxidizing species on the 136 reactivity of iron-based bimetallic reductants. Environ. Sci. Technol. 41 (2007), 3734-3740.

137 [16] A.F. White, M.L. Peterson, Reduction of aqueous transition metal species on the surfaces 138 of Fe(II)-containing oxides. Geochimica et Cosmochimica Acta 60 (1996), 3799-3814.

139 [17] B.D. Jones, J.D. Ingle, Evaluation of redox indicators for determining sulfate-reducing

140 and dechlorinating conditions. Water Res. 39 (2005), 4343-4354.

141 [18] B. Little, P. Wagner, F. Mansfeld, An overview of microbiologically influenced 142 corrosion. Electrochim. Acta 37 (1992), 2185-2194. 